\title{
Accumulation of lysosulfatide in the brain of arylsulfatase A-deficient mice
}

\author{
Maria Blomqvist ${ }^{1 *}$, Volkmar Gieselmann², Jan-Eric Månsson ${ }^{1}$
}

\begin{abstract}
Lysosomal storage diseases are a group of disorders where accumulation of catabolites is manifested in the lysosomes of different cell types. In metachromatic leukodystrophy (Arylsulfatase A [EC.3.1.6.8] deficiency) storage of the glycosphingolipid sulfatide in the brain leads to demyelination, resulting in neuromotor co-ordination deficits and regression. In a mouse model for metachromatic leukodystrophy, the ASA null mutant mouse, the accumulation of sulfatide in correlation to phenotype has been thoroughly investigated. Another lipid species reported to accumulate in patients with metachromatic leukodystrophy is the sulfatide related lipid lysosulfatide. Lysosulfatide was shown to be a cytotoxic compound in cell culture experiments and thus suggested to be involved in the pathology of metachromatic leukodystrophy. In this study, we further investigated the developmental profile of lysosulfatide in the brain of ASA null mutant mice by using high performance liquid chromatography. Lysosulfatide could be detected in the brain of normal mice (ASA $+/+$ ) from 1.8 months up to 23.1 months of age. From the age of 8.8 months the lysosulfatide levels remained constant at $1 \mathrm{pmol} / \mathrm{mg}$ wet tissue. The developmental change ( $<20$ months) of brain lysosulfatide showed an accumulation in ASA null mutant mice at ages above one month compared to its normal counterpart (ASA +/+). Thus, the ASA null mutant mouse might be a suitable model to further investigate the role of lysosulfatide in the pathogenesis of metachromatic leukodystrophy.
\end{abstract}

\section{Introduction}

The hypothesis of lysosphingolipids being cytotoxic catabolites in leukodystrophies was put forward in 1972 by Miyatake and Suzuki [1]. They investigated globoid cell leukodystrophy (Krabbe disease), caused by a deficiency of galactosylceramidase, and found increased concentrations of galactosylsphingosine (psychosine) in post-mortem brain tissue. The accumulation of galactosylsphingosine in the Krabbe brains was confirmed by Svennerholm et al. who also structurally characterized the isolated compound [2]. An accumulation of galactosylsphingosine was also shown in the natural mouse model for Krabbe disease, the twitcher mouse [3,4], and a close relationship between the abnormal abundance of galactosylsphingosine and demyelination was suggested. In other lysosomal storage diseases (LSDs), such as Gaucher disease, GM1 and GM2 gangliosidoses, Niemann-Pick type A and Fabry disease, abnormal

\footnotetext{
* Correspondence: maria.k.blomqvist@vgregion.se

'Department of Psychiatry and Neurochemistry, Institute of Neuroscience and Physiology, University of Gothenburg, Sweden Full list of author information is available at the end of the article
}

accumulations of lysosphingolipids in various tissues have also been shown [5-10].

Metachromatic leukodystrophy (MLD) is an autosomal recessive inherited LSD (OMIM 250100) where the enzyme arylsulfatase A (ASA, EC. 3.1.6.8) is deficient [11]. Due to this enzyme deficiency, galactosylceramide3-O-sulfate (Sulfatide, Figure 1) accumulates within the lysosomes of various tissues. Sulfatide is a major component of the myelin sheet in the nervous system and accumulation of sulfatide in oligodendrocytes of this region leads to severe demyelination. However, sulfatide is probably not responsible for the complete demyelination process since this compound is a natural non-toxic component of brain myelin. Furthermore, the accumulation of sulfatide does not accompany the demyelination in some MLD patients [12].

Another lipid species reported to accumulate in patients with MLD is lysosulfatide (the deacylated form of sulfatide or sulfogalactosylsphingosine, Figure 1) $[13,14]$. Lysosulfatide is considered to be a cytotoxic substance in vitro, where $150 \mu \mathrm{M}$ lysosulfatide showed a $50 \%$ inhibition of protein kinase $\mathrm{C}[15]$ and $50-100 \mu \mathrm{M}$
C Biomed Central 


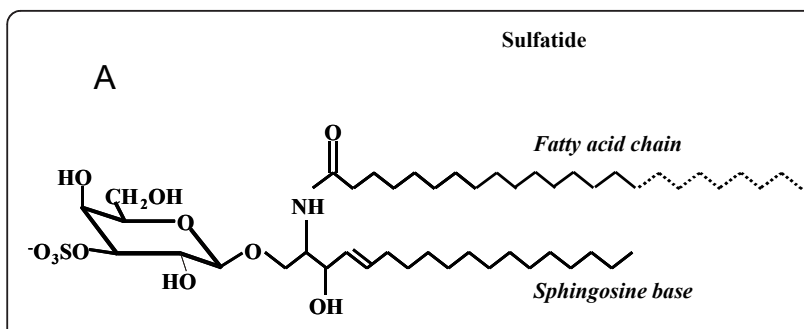

B

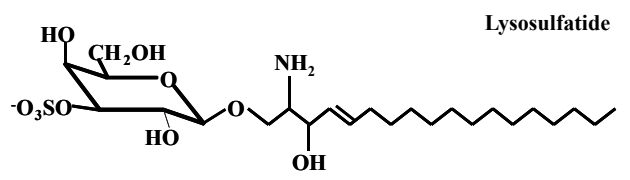

Figure 1 Sulfatide (A) and lysosulfatide (B) structures. The glycosphingolipid sulfatide (galactosylceramide-3-O-sulfate) consists of a ceramide backbone (i.e. a long-chain base and a fatty acid chain) and a sulfated galactose moiety. Lysosulfatide is the deacylated form of sulfatide (sulfogalactosylsphingosine).

inhibited cytochrome c oxidase activity [13]. Furthermore, lysosulfatide sulfatase is deficient in MLD fibroblasts [16]. Recent studies have also shown regulatory functions of lysosulfatide using neuronal precursor cells, where lysosulfatide inhibited cell migration via calciummediated process collapse [17].

The ASA null mutant mouse model created by Hess et al [18] was shown to have no ASA enzyme activity and the pattern of lipid storage resembles that of the human situation. The most severe form of MLD in humans (late infantile), which is caused by a complete lack of ASA activity, is associated with progressive demyelination, neuromotor co-ordination deficits and regression. However, the ASA null mutant mice (no ASA activity) show an attenuated phenotype compared with MLD patients with no enzyme activity. The animals display demyelination of the peripheral nervous system, astrogliosis and aberrant morphology of Bergmann glia and cerebellum [19]. Furthermore, mice become deaf and show various neuromotor abnormalities.

The aim of this study was to investigate the occurrence and developmental profile of lysosulfatide in an ASA null mutant mouse model by using high performance liquid chromatography (HPLC).

\section{Materials and methods}

Animals and animal tissues

Chimeric male mice obtained by injection of embryonic stem cells with targeted disruption of the ASA gene into blastocysts [18] were mated with C57BL/6J wildtype females. The offspring were analyzed by Southern blot analysis of tail DNA for the presence of the disrupted ASA allele. Mice heterozygous for the knockout allele
(ASA +/-) were mated to obtain ASA-deficient (ASA $-/-)$ and wildtype control mice (ASA $+/+$ ). Animals were bred under standard conditions and all experimental protocols were performed with due permission from the appropriate local and national authorities.

For lipid analyses, mice were anaesthetized with $\mathrm{CO}_{2}$ and killed by cervical dislocation. The brains were dissected out (the cerebellum and medulla oblongata were removed), immediately frozen in liquid nitrogen and stored at $-80^{\circ} \mathrm{C}$. ASA $-/$ - mice were examined at $1.1,4.2$, 9.2, 15.6, 18.5 and 20.6 months of age with $2-4$ animals in each group. ASA $+/+$ mice were examined at 1.8, 4.9, 8.8, 13.0, 16.3, 17.2 and 23.1 months of age with 1-4 animals in each group.

\section{Lipids}

Lysosulfatide and glucosylsphingosine used as calibrators were produced and characterized at the Neurochemistry laboratory, Mölndal, Sweden [20]. The structure of synthesized lysosphingolipids was confirmed with electrospray ionization-mass spectrometry (quadrupoletime-of-flight, Micromass, Manchester, UK). Radiolabelling of lysosulfatide was performed according to the method by Schwarzmann et al [21].

\section{Lipid extraction and separation}

Frozen brains were mortared under liquid nitrogen and approximately $100 \mathrm{mg}$ of the homogenized brain powder was taken for lipid extraction with chloroform:methanol: water, (C/M/W 4:8:3, by vol.) [22]. From the lipid extract, an aliquot corresponding to approximately $10 \mathrm{mg}(1 / 10)$ homogenized brain powder was evaporated and resolved in $5 \mathrm{~mL}$ methanol/1M $\mathrm{KOH}(9 / 1$ by vol,). Saponification was performed at $37^{\circ} \mathrm{C}$ for $2 \mathrm{~h}$ after which $5 \mathrm{~mL}$ water was added.

The brain extracts were further purified on LCR-C18 columns (Varian Inc, Palo Alto, CA, USA). The LCR-C18 column was activated and washed with 10 bed volumes of methanol and C/M (1:2 by vol.) respectively, followed by 20 bed volumes of methanol and water, respectively. The sample was applied to the column and subsequently 80 bed volumes of water. Lysosulfatide was eluted with 20 bed volumes of M/W (62/38 by vol.) and an internal standard (glucosylsphingosine, $300 \mathrm{pmol}$ ) was then added to each sample. The sample was evaporated, resolved in $100 \mu \mathrm{L}$ methanol and derivatized as described below.

The recovery of lysosulfatide was determined by adding ${ }^{3} \mathrm{H}$-lysosulfatide (corresponding to $830 \mathrm{~Bq}$ ) to the lipid extract from brain tissue, as described above. The amount of ${ }^{3} \mathrm{H}$-lysosulfatide in the "lysosulfatide fraction" eluted from the LCR-C18 column was determined by scintillation counting (Perkin Elmer Tri-Carb 2800 TR, MA, US) and the recovery was 50\% throughout the whole procedure (triplicates, data not shown). 


\section{Calibrators}

Calibrators for lysosulfatide quantification were prepared from stock solutions $(1 \mathrm{nmol} / 50 \mu \mathrm{L}$ methanol) and amounts of 10, 25, 50,100, 250, 500 and 1000 pmol were used. The internal calibrator glucosylsphingosine (300 pmol) was added to each standard. The volume was corrected to $100 \mu \mathrm{L}$ by adding methanol to each standard. Calibrators were $\mathrm{N}$-derivatized with $40 \mu \mathrm{L}$ O-phthalaldehyde-(OPA) (Pierce, Illinois, US) for 15 minutes at RT. The detection limit for lysosulfatide was approximately 2 pmol.

\section{Quantification of lysosulfatide}

Lysosulfatide and glucosylsphingosine were $\mathrm{N}$-derivatized with $40 \mu \mathrm{L}$ OPA (Pierce) for 15 minutes at RT. Chromatography was performed by the HPLC Varian 9010 system, fitted with a Genesis C18 column $(4 \mu \mathrm{m}$, $150 \times 3 \mathrm{~mm}$, Jones Chromatography, UK). The mobile phase was methanol-35 mM phosphoric acid in water (835:165 by vol.) with a flow rate of $1.0 \mathrm{~mL} \mathrm{~min}^{-1}$. A JASCO 821-FP spectrofluorometer with excitation at $335 \mathrm{~nm}$ and emission at $420 \mathrm{~nm}$ wavelengths was used for peak detection. Data were collected by PE NELSON chromatography software (Perkin Elmer Inc., MA, US).

\section{Evaluation}

The amount of lysosulfatide in the samples was calculated using the respective standard curve, as described above. The quota of lysosulfatide/glucosylsphingosine (pmol) was calculated for each sample and multiplied by 2 for correction of the $50 \%$ recovery of lysosulfatide throughout the whole procedure. Values are expressed as mean $\pm \mathrm{SD}$.

\section{Results}

Lysosulfatide could be detected in the brain of normal mice (ASA +/+) from the age of 1.8 months. From the age of 8.8 months, the lysosulfatide levels remained constant at $1 \mathrm{pmol} / \mathrm{mg}$ wet tissue (Figure 2). The lysosulfatide levels in the ASA -/- animals increased with age and peaked around 18.5 months of age $(30 \mathrm{pmol} / \mathrm{mg}$ wet tissue) followed by a slight decline (Figure 2).

\section{Discussion}

This investigation shows an accumulation of the lysosphingolipid lysosulfatide in the brain of Arylsulfatase A deficient mice (ASA -/-), a murine model for the human disease Metachromatic Leukodystrophy (MLD). This finding is in agreement with previous studies on post mortem brain tissues from MLD patients [13,14], where quantification of lysosulfatide used internal standards in a similar way as described above. However, one study by Rosengren et al. is not supportive [23]. The reason for this contradictory result might be the choice of method

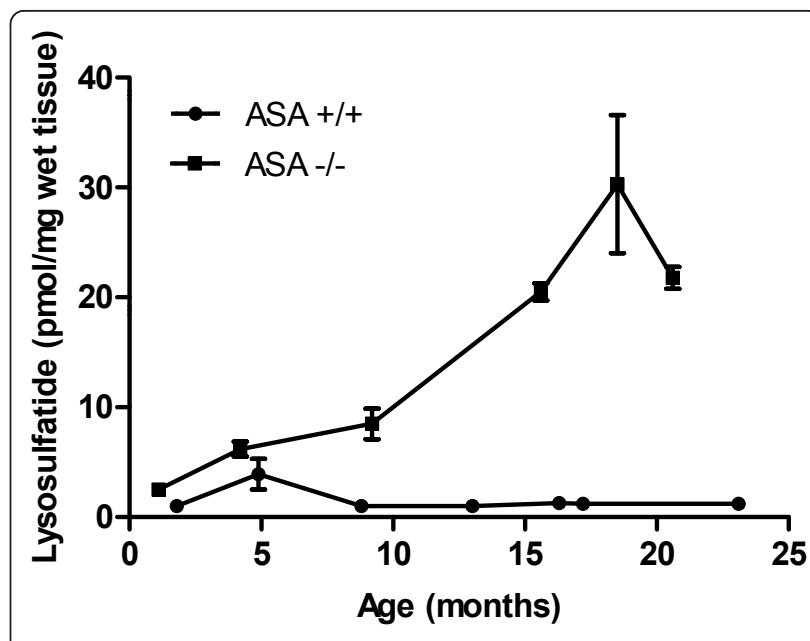

Figure $\mathbf{2}$ Lysosulfatide accumulates in brain from arylsulfatase A-deficient mice. Graphs show developmental profiles of lysosulfatide in ASA -/- mouse brains (squares) and ASA +/+ mouse brains (circles). Each age group contained 2-4 animals for ASA -/mice and 1-4 animals for ASA +/+ mice. The mean value for each age group was calculated, as well as the corresponding SD. Error bars represents the SD of the mean.

in the study by Rosengren et al., where radioimmunoaffinity TLC was used for quantification, or possibly the quality of the brain tissue.

Since the accumulation of lysosphingolipids has been observed in many of the sphingolipidoses [2,5-10], it seems reasonable that these substances might play a role in the pathogenesis of LSDs. Several studies also support this role, mainly as cytotoxic compounds. The most thoroughly investigated lyso-compound is the lysosphingolipid of galactosylceramide, psychosine, which accumulates in Krabbe disease [1,2,24]. The accumulation is closely related to the demyelination process and it is suggested to involve several mechanisms. These include regulating protein kinase $\mathrm{C}$ mediated growth factor, interfering with IGF-1 signalling, activating phospholipiase A2 and thus producing lysophosphatidylcholine-induced apoptosis and activating TDAG8 receptors resulting in the production of multinuclear globoid cells, reviewed by [25]. One might assume similar mechanisms being involved in the pathogenesis of MLD but this remains to be investigated. Thus, the observation of accumulated lysosulfatide in the ASA -/- mouse suggests this model to be a suitable tool for functional studies of lysosulfatide in the pathogenesis of MLD.

It must be mentioned that the ASA deficient mouse does not demyelinate in the central nervous system [18]. In this respect it is interesting to compare the lysosulfatide levels found in patients who develop demyelination. In the white matter of MLD patients, levels ranging from 50-200 $\mathrm{pmol} / \mathrm{mg}$ wet weight of lysosulfatide have been found $[13,14]$. These levels are higher than those 
found in the non demyelinating mice. Furthermore, the concentrations of lysosulfatide were found to be similar when comparing human control cerebral white matter with the brain of ASA $+/+$ mice. Thus, if lysosulfatide is indeed a major cause of demyelination in MLD the comparatively low levels found in ASA -/- mice would explain the lack of demyelination in this animal model.

Lipid rafts, enriched in cholesterol and sphingolipids, act as scaffolds on which different signalling molecule assemble [26]. These domains play a central role in many cellular processes including membrane sorting and trafficking, signal transduction, cell growth and survival. The list of various diseases where raft formation plays an important role in disease progression continues to grow [27] and includes the possibility of these domains being involved at a cellular level in the pathogenesis of LSDs. White et al. recently showed an accumulation of psychosine in rafts isolated from the post mortem brain of human Krabbe patients and from brain and sciatic nerve of the twitcher mouse [28]. Psychosine accumulation was accompanied by increased levels of cholesterol in these domains and changes in the distribution of the raft markers flotilin-1 and caveolin-1. Furthermore, these molecular changes were associated with the inhibitory effect of psychosine on protein kinase $C$. The authors propose a model of psychosine involvement in raft-modulated cell functions by disrupting the raft architecture and deregulating signal activity (disorganisation of myelin components, inflammation, synaptic dysfunction, axonal defects). Since the ethiology of MLD is somewhat similar to Krabbe disease, it is reasonable to assume that raft disruption involving lysosulfatide accumulation might play a role in disease progression. However, the accumulation of lysosulfatide in rafts of MLD patients and ASA mice remains to be investigated.

\section{Conclusion}

In agreement with the accumulation of lysosulfatide in the brain of patients with metachromatic leukodystrophy, ASA null mutant mice also showed increased amounts of this lysosphingolipid in the brain. Furthermore, a developmental increase of lysosulfatide was observed. Lysosulfatide is considered to be a possible pathogenic agent in MLD contributing to the severe demyelination occurring in these patients. However, the mechanism of involvement is not known. The ASA null mutant mice might be a suitable model to investigate the role of lysosulfatide in the pathogenesis of MLD, including the peripheral demyelination of these animals.

\footnotetext{
Abbreviations

ASA: arylsulfatase A; HPLC: high performance liquid chromatography; LSD: lysosomal storage disease; MLD: metachromatic leukodystrophy; OPA:
}

O-phthalaldehyde; Sulfatide: galactosylceramide-3-O-sulfate; Lysosulfatide: sulfogalactosylsphingosine

\section{Acknowledgements}

We acknowledge Natascha Svensson for technical assistance. This work was supported by grants from the Swedish Research Council (K2004-03X-0990911C).

\section{Author details}

${ }^{1}$ Department of Psychiatry and Neurochemistry, Institute of Neuroscience and Physiology, University of Gothenburg, Sweden. ${ }^{2}$ Institute fur Physiologische Chemie, Universität Bonn, Germany.

\section{Authors' contributions}

JEM designed the study, MB analysed the data and drafted the paper and VG provided the tissue material. All the authors contributed to the interpretation and discussion of the results related to their part of the work, critically revised the paper and read and approved the final manuscript.

\section{Competing interests}

The authors declare that they have no competing interests.

Received: 11 January 2011 Accepted: 7 February 2011

Published: 7 February 2011

\section{References}

1. Miyatake T, Suzuki K: Globoid cell leukodystrophy: additional deficiency of psychosine galactosidase. Biochem Biophys Res Commun 1972 48(3):539-543.

2. Svennerholm L, Vanier MT, Mansson JE: Krabbe disease: a galactosylsphingosine (psychosine) lipidosis. J Lipid Res 1980, 21(1):53-64.

3. Tanaka K, Nagara H, Kobayashi T, Goto l: The twitcher mouse: accumulation of galactosylsphingosine and pathology of the central nervous system. Brain Res 1989, 482(2):347-350.

4. Esch SW, Williams TD, Biswas S, Chakrabarty A, Levine SM: Sphingolipid profile in the CNS of the twitcher (globoid cell leukodystrophy) mouse: a lipidomics approach. Cell Mol Biol (Noisy-le-grand) 2003, 49(5):779-787.

5. Nilsson O, Svennerholm L: Accumulation of glucosylceramide and glucosylsphingosine (psychosine) in cerebrum and cerebellum in infantile and juvenile Gaucher disease. J Neurochem 1982, 39(3):709-718.

6. Rosengren B, Mansson JE, Svennerholm L: Composition of gangliosides and neutral glycosphingolipids of brain in classical Tay-Sachs and Sandhoff disease: more lyso-GM2 in Sandhoff disease? J Neurochem 1987, 49(3):834-840.

7. Kobayashi T, Goto I, Okada S, Orii T, Ohno K, Nakano T: Accumulation of lysosphingolipids in tissues from patients with GM1 and GM2 gangliosidoses. J Neurochem 1992, 59(4):1452-1458.

8. Neuenhofer S, Conzelmann E, Schwarzmann G, Egge H, Sandhoff K: Occurrence of lysoganglioside lyso-GM2 (II3-Neu5Acgangliotriaosylsphingosine) in GM2 gangliosidosis brain. Biol Chem Hoppe Seyler 1986, 367(3):241-244

9. Rodriguez-Lafrasse C, Vanier MT: Sphingosylphosphorylcholine in Niemann-Pick disease brain: accumulation in type A but not in type B. Neurochem Res 1999, 24(2):199-205.

10. Aerts JM, Groener JE, Kuiper S, Donker-Koopman WE, Strijland A, Ottenhoff R, van Roomen C, Mirzaian M, Wijburg FA, Linthorst GE, et al: Elevated globotriaosylsphingosine is a hallmark of Fabry disease. Proc Natl Acad Sci USA 2008, 105(8):2812-2817.

11. von Figura K, Gieselmann V, Jaecken J: Metachromatic leukodystrophy: Lysosomal disorders. In The Metabolic and Molecular Bases of Inherited Disease. Edited by: Scriver CR, Beaudet AL, Sly WS, Valle D. New York: McGraw-Hill; 2001:3695-3724.

12. Norton WT, Poduslo SE: Biochemical studies of metachromatic leukodystrophy in three siblings. Acta Neuropathol 1982, 57(2-3):188-196.

13. Toda K, Kobayashi T, Goto I, Kurokawa T, Ogomori K: Accumulation of lysosulfatide (sulfogalactosylsphingosine) in tissues of a boy with metachromatic leukodystrophy. Biochem Biophys Res Commun 1989, 159(2):605-611.

14. Toda K, Kobayashi T, Goto I, Ohno K, Eto Y, Inui K, Okada S: Lysosulfatide (sulfogalactosylsphingosine) accumulation in tissues from patients with metachromatic leukodystrophy. J Neurochem 1990, 55(5):1585-1591. 
15. Hannun YA, Bell RM: Lysosphingolipids inhibit protein kinase C: implications for the sphingolipidoses. Science 1987, 235(4789):670-674.

16. Eto Y, Wiesmann U, Herschkowitz NN: Sulfogalactosylsphingosine sulfatase. Characteristics of the enzyme and its deficiency in metachromatic leukodystrophy in human cultured skin fibroblasts. J Biol Chem 1974, 249(15):4955-4960,

17. Hans M, Pusch A, Dai L, Racke K, Swandulla D, Gieselmann V, Kappler J: Lysosulfatide regulates the motility of a neural precursor cell line via calcium-mediated process collapse. Neurochem Res 2009, 34(3):508-517.

18. Hess B, Saftig P, Hartmann D, Coenen R, Lullmann-Rauch R, Goebel HH, Evers M, von Figura K, D'Hooge R, Nagels G, et al: Phenotype of arylsulfatase A-deficient mice: relationship to human metachromatic leukodystrophy. Proc Natl Acad Sci USA 1996, 93(25):14821-14826.

19. Gieselmann V, Matzner U, Hess B, Lullmann-Rauch R, Coenen R, Hartmann D, D'Hooge R, DeDeyn P, Nagels G: Metachromatic leukodystrophy: molecular genetics and an animal model. J Inherit Metab Dis 1998, 21(5):564-574.

20. Blomqvist M, Carrier M, Andrews T, Pettersson K, Månsson JE, Rynmark BM, Fredman $P$, Buschard $K$ : In vivo administration of the C16:0 fatty acid isoform of sulfatide increases pancreatic sulfatide and enhances glucose stimulated insulin secretion in Zucker fatty $(\mathrm{fa} / \mathrm{fa})$ rats. Diabetes Metab Res Rev 2005, 21(2):158-166.

21. Schwarzmann G: A simple and novel method for tritium labeling of gangliosides and other sphingolipids. Biochim Biophys Acta 1978, 529(1):106-114.

22. Svennerholm L, Fredman P: A procedure for the quantitative isolation of brain gangliosides. Biochim Biophys Acta 1980, 617(1):97-109.

23. Rosengren B, Fredman P, Månsson JE, Svennerholm L: Lysosulfatide (galactosylsphingosine-3-O-sulfate) from metachromatic leukodystrophy and normal human brain. J Neurochem 1989, 52(4):1035-1041.

24. Kobayashi T, Goto I, Yamanaka T, Suzuki Y, Nakano T, Suzuki K: Infantile and fetal globoid cell leukodystrophy: analysis of galactosylceramide and galactosylsphingosine. Ann Neurol 1988, 24(4):517-522.

25. Ballabio A, Gieselmann V: Lysosomal disorders: from storage to cellular damage. Biochim Biophys Acta 2009, 1793(4):684-696.

26. Lingwood D, Simons K: Lipid rafts as a membrane-organizing principle. Science 2010, 327(5961):46-50.

27. Simons K, Ehehalt R: Cholesterol, lipid rafts, and disease. J Clin Invest 2002, 110(5):597-603.

28. White AB, Givogri MI, Lopez-Rosas A, Cao H, van Breemen $\mathrm{R}$, Thinakaran $\mathrm{G}$ Bongarzone ER: Psychosine accumulates in membrane microdomains in the brain of krabbe patients, disrupting the raft architecture. J Neurosci 2009, 29(19):6068-6077.

doi:10.1186/1476-511X-10-28

Cite this article as: Blomqvist et al.: Accumulation of lysosulfatide in the brain of arylsulfatase A-deficient mice. Lipids in Health and Disease 2011 $10: 28$

\section{Submit your next manuscript to BioMed Central and take full advantage of:}

- Convenient online submission

- Thorough peer review

- No space constraints or color figure charges

- Immediate publication on acceptance

- Inclusion in PubMed, CAS, Scopus and Google Scholar

- Research which is freely available for redistribution 